\title{
Ocupação no setor público brasileiro: tendências recentes e questões em aberto
}

José Celso Cardoso Júnior e Roberto Passos Nogueira

\section{Apresentação}

Este texto resume parte dos resultados da pesquisa que redundou no livro Burocracia e Ocupação no Setor Público Brasileiro, que constitui o quinto volume da série Diálogos para o Desenvolvimento do Ipea. ${ }^{1}$

A proposta do referido livro surgiu em 2008 da parceria entre o Ipea e a Secretaria de Recursos Humanos do Ministério do Planejamento, Orçamento e Gestão (SRH/MPOG). Naquela ocasião, o governo federal estava sob críticas severas, entre outros motivos, por causa da política que estava em curso de revalorização dos servidores públicos, recomposição de pessoal e de sua remuneração. Basicamente, os ataques focavam em duas questões: o suposto inchaço da máquina pública federal e o suposto descontrole fiscal advindo da mencionada política.

Após dois anos de pesquisa destinada a reunir e organizar informações de qualidade sobre o tema, bem como a melhor entender e interpretar os resultados 
de inúmeras tabulações que tiveram como fonte praticamente todas as principais bases de dados secundários disponíveis - como os Censos Demográficos, a Pesquisa Nacional por Amostra de Domicílios (Pnad), a Relação Anual de Informações Sociais (Rais) e o Sistema Integrado de Administração de Recursos Humanos (Siape) -, pode-se hoje afirmar com maior segurança que:

1) O movimento de recomposição de pessoal no setor público brasileiro, observado durante toda a primeira década de 2000, não foi explosivo e se mostrou suficiente para repor praticamente o mesmo estoque e percentual de servidores ativos existentes em meados da década de 1990.

2) Ao longo do período em estudo, houve, em particular, uma preocupação compensar, portanto, o número dos que se aposentaram anualmente ao longo dessas duas décadas (Gráfico 1). Contudo, o pico de cerca de 680 mil servidores civis ativos de 1992 ainda não foi alcançado.

O significado da retomada do concurso público para crescimento e fortalecimento da capacidade de Estado fica bem evidenciado no Gráfico 2, que consolida a série de admitidos anualmente a partir dos governos Collor e Itamar, durante os quais não houve admissão de servidores por essa via. Nada menos que 155 mil novos servidores foram admitidos entre 2003 e 2010. O número de servidores ativos civis em 2010 ainda era menor que no início da década de 1990, entre outros fatores, pelo fato de que houve ao menos três momentos importantes de corrida à aposentadoria. De

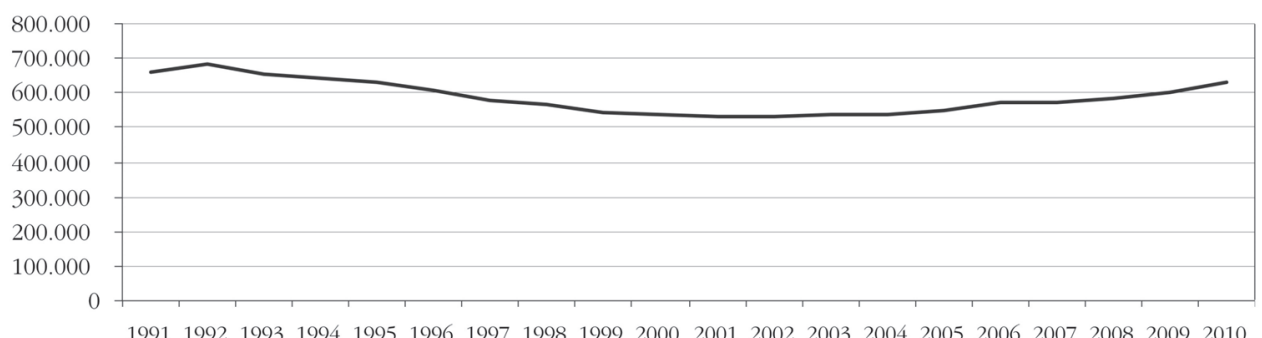

Fonte: Boletim Estatístico de Pessoal, SRH/MPOG. Elaboração própria.

\section{Gráfico 1: Servidores Civis Ativos da Administração Federal, 1991-2010}

em conferir maior capacidade burocrática ao Estado brasileiro, mediante reforço a carreiras em áreas estratégicas, tais como: advocacia pública, arrecadação e finanças, controle administrativo, planejamento e regulação.

Com a retomada dos concursos públicos, o número de servidores civis ativos da administração federal voltou ao patamar de mais de 600 mil, vigente na primeira metade dos anos 1990, vindo a modo geral, os anos com maior concessão de aposentadorias coincidem com três períodos que precederam ou acompanharam reformas previdenciárias: 1991, 1995 a 1998 e 2003.

Em 2010, pode-se perceber um prenúncio de nova elevação do número das aposentadorias, que se coloca acima de 10 mil por ano. Isto ocorre devido à decisão de servidores em condições legais de se aposentarem, de retardarem ou 
anteciparem sua solicitação, conforme a conjuntura lhes pareça mais ou menos favorável ou desfavorável aos seus direitos.

3) Tampouco se deduz dos dados analisados que os gastos com pessoal tenham saído do controle do governo federal, pois, em termos percentuais (Gráfico 3), essa rubrica permaneceu praticamente constante ao longo da primeira década de 2000, em um contexto de retomada relativa do crescimento econômico e também da arrecadação tributária.

4) Do ponto de vista qualitativo, evidências da pesquisa indicam que o movimento atual de recomposição de pessoal no setor público deve trazer melhorias gradativas ao desempenho institucional, talvez ainda pouco perceptíveis em função do insuficiente tempo de maturação do novo contingente de força de trabalho a serviço do Estado, uma vez que esses servidores:

- vêm sendo selecionados a partir de critérios meritocráticos, por meio de concursos públicos, e mais para atividadesfim, que exigem nível superior de escolarização, do que para atividades-meio, indicando a possibilidade de maiores impactos sobre a produtividade agregada do setor público; e

- têm assumido a forma de vinculação estatutária, em detrimento do padrão

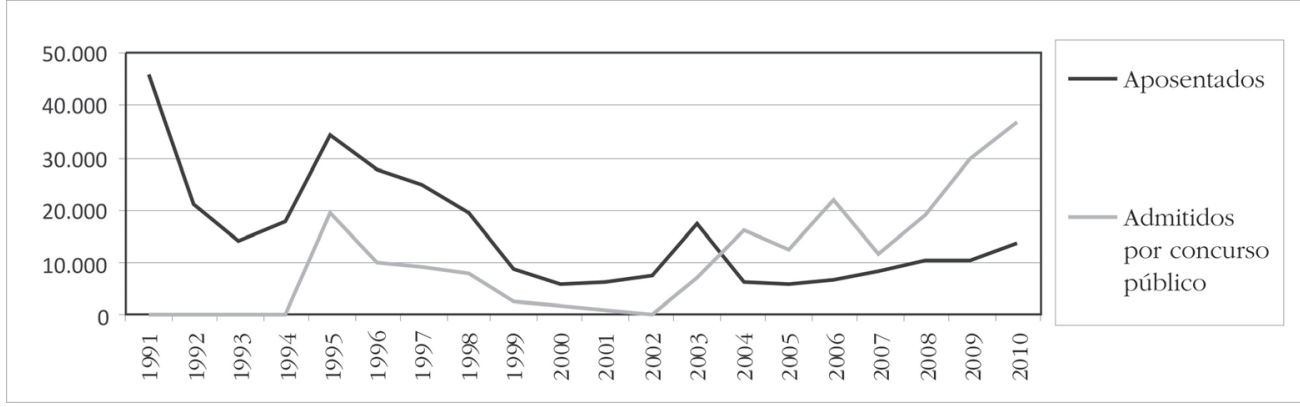

Fonte: Boletim Estatístico de Pessoal, SRH/MPOG. Elaboração própria.

Gráfico 2: Servidores Civis Federais: aposentados e admitidos por concurso

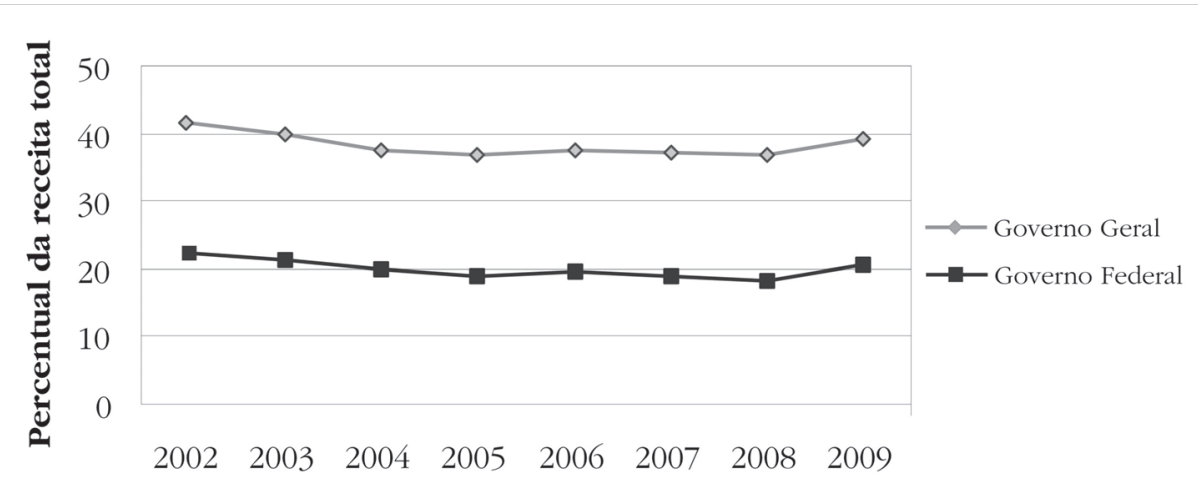

Fonte: Tesouro Nacional

Gráfico 3: Despesas de pessoal como percentual da arrecadação 
celetista ou de várias formas de contratação precárias, o que os coloca sob direitos e deveres comuns e estáveis, podendo com isso gerar mais coesão e homogeneidade no interior da categoria, aspecto considerado essencial para um desempenho satisfatório do Estado a longo prazo.

Apresentam-se, na seção 2, razões históricas gerais pelas quais o Estado, em qualquer momento ou local, assume esta ou aquela configuração institucional, em termos de pessoas ocupadas no setor público. Após isso, na seção 3, apresentam-se dados estatísticos que desagregam as informações gerais antecipadas nesta introdução, visando caracterizar determinadas tendências recentes acerca do assunto no Brasil, tais como: o crescimento mais que proporcional dos vínculos privados, relativamente aos públicos, ao longo da primeira década de 2000; a municipalização da ocupação no setor público; a substituição de terceirizados por servidores concursados sob regime jurídico único, e de pessoal administrativo (áreasmeio) por pessoal técnico em áreas finalísticas da ação estatal; o aumento da escolarização e profissionalização da força de trabalho ocupada no setor público, bem como o aumento da presença feminina na ocupação pública; e, ainda, tendências recentes em termos dos gastos com pessoal frente a agregados, como o PIB, a arrecadação tributária e a massa salarial do setor privado. Por fim, na seção 4, resumem-se argumentos e elencam-se alguns pontos considerados urgentes e estratégicos nesta atividade de pesquisa aplicada, bem como para assessoramento do Ipea em torno deste assunto.

\section{De que é composto o Estado?}

De que é composto o Estado? O que explica sua formação e composição em termos de recursos humanos, físicos, tecnológicos, normativos etc.? O que explica as mudanças nas formas de atuação e nas próprias áreas de atuação dos estados modernos? Por que o "tamanho" do Estado passou a ser uma obsessão da mídia e de determinados setores da sociedade, no Brasil e em outros lugares?

Essas e outras questões não possuem respostas rápidas nem fáceis. De todo modo, em termos gerais, seria possível dizer que respostas a essas intrincadas questões passam pelo entendimento de que o "tamanho" do Estado, a cada momento histórico e geográfico específico, estaria a refletir uma somatória ampla e provavelmente contraditória de processos sociopolíticos simultâneos, destinados, quase todos, a tentar transformar o Estado melhor seria dizer seus diferentes e heterogêneos segmentos, aparelhos e instituições em um agente de indução ou mesmo de transformação das estruturas econômicas e sociais de determinado país ou região. Transformações que, historicamente, assumiram formatos e conteúdos variados, espelhando tanto interesses particulares de determinada classe ou fração de classe no poder quanto, talvez, interesses nacionais a serviço do bem comum. Devemos lembrar, ainda, da possibilidade de que possam espelhar interesses autocentrados no próprio Estado ou exclusivos de parte da burocracia estatal - também geralmente hegemônica - em cada caso.

Buscando exemplificar um pouco o que foi dito no parágrafo anterior, e atendo-se - para facilitar e manter o foco no tema - apenas à dimensão relativa à composição da força de trabalho ocupada no setor público, em um caso imaginário qualquer, suponhamos configurações de Estado derivadas dos três casos hipotéticos citados. 
No primeiro caso, o quantitativo de pessoal reflete decisões de um Estado voltado a satisfazer interesses particulares de determinada classe ou fração de classe hegemônica no poder, exatamente como em certos casos de estados monárquicos e estados mercantilistas de caráter despótico do século XVI ao XIX. É de se supor que, neste caso, haja muitas pessoas ocupadas em torno do cumprimento de funções ligadas à soberania externa - Forças Armadas e diplomacia - e à segurança interna - polícias e demais aparatos de fiscalização e repressão -, em detrimento tanto de ocupações ligadas à provisão de bens e serviços públicos ao conjunto amplo da população quanto ao fortalecimento dos mercados econômicos domésticos.

No segundo caso, em que o pessoal ocupado no setor público reflete interesses nacionais ou universais a serviço do bem comum, é plausível assumir a existência de contingentes consideráveis de trabalhadores inseridos em atividades relacionadas à provisão de bens e serviços públicos à população, em áreas que são, por sua própria natureza, bastante intensivas em pessoas, tais como: saúde, educação, assistência social, segurança pública, transporte público, entre outras. Também seria de se esperar, neste caso, que houvesse preocupação equivalente - e pessoal empregado - em áreas indelegáveis de atuação dos estados capitalistas contemporâneos, sempre que interessados na sustentação atemporal de estratégias de desenvolvimento ancoradas ou voltadas aos mercados e populações nacionais. Tais áreas ou atividades de atuação estatal estariam ligadas, grosso modo, ao desempenho das seguintes funções: i) o monopólio estatal da representação e da defesa nacional externa; ii) o monopólio do uso da violência para a segurança pública interna; iii) o monopólio da formulação e imposição das leis; $i v$ ) o monopólio da implementação e gestão da moeda; v) o monopólio da tributação; $v$ ) a garantia e a proteção da propriedade privada; vii) a geração de confiança na validade e cumprimento dos contratos; viii) a estabilidade do valor real da moeda; ix) a regulação do conflito distributivo e $x$ ) a garantia de previsibilidade para a rentabilidade empresarial privada.

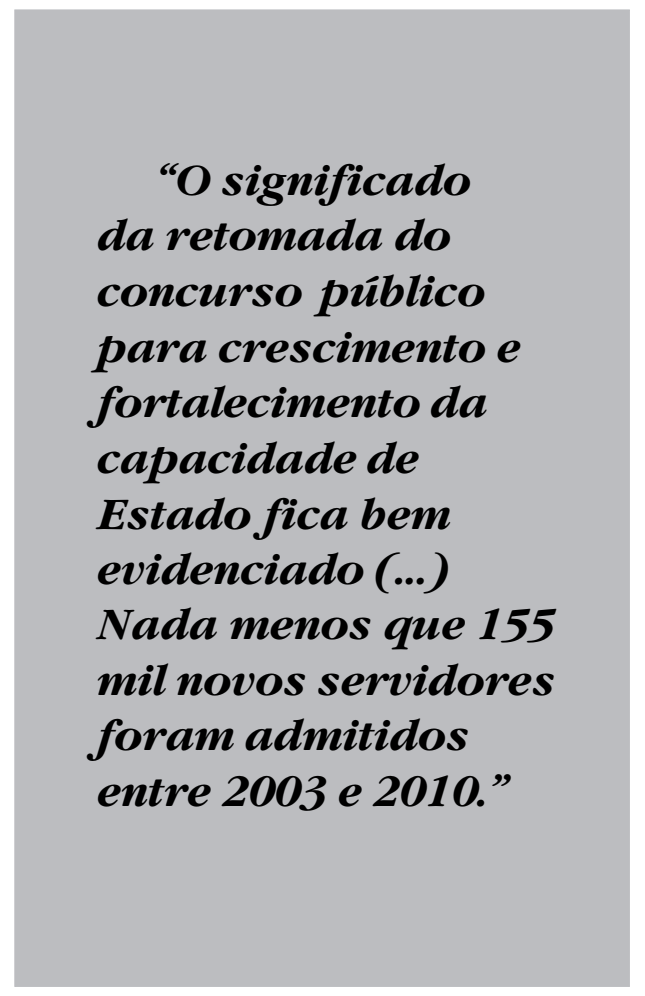

Por fim, no caso em que a força de trabalho no setor público venha a espelhar interesses autocentrados no próprio Estado ou em parte, normalmente hegemônica, da burocracia estatal, não seria exagero concluir por uma concentração proporcionalmente desbalanceada de servidores em atividades-meio, mais que em atividades-fim. Adicionalmente, haveria muitos funcionários menos qualificados e 
capacitados, com menos motivação e mal remunerados, em um leque grande de atividades costumeiramente voltadas ao relacionamento direto com a população; assim, haveria poucos funcionários, em geral mais qualificados, capacitados, motivados e bem remunerados, em algumas atividades consideradas centrais pela burocracia hegemônica no poder. Historicamente, não é difícil identificar essa configuração como caso clássico de criação e perpetuação - às vezes longa de determinadas "ilhas de excelência" na administração pública, convivendo com significativa parcela de servidores atuando em situação precária e em atividades que demandam baixa qualificação, como é o caso de vários países subdesenvolvidos da América Latina (incluindo o Brasil), África, Leste Europeu e Sudeste Asiático, ao longo do século XX.

Ainda que no mundo concreto as situações reais sejam fruto de um intercâmbio dos três tipos ideais citados, os quais se modificam - para dificultar as análises - ao longo do tempo e das circunstâncias históricas particulares, conclui-se que não se pode, sob hipótese alguma, falar de "tamanho" do Estado, ou mesmo do "quantitativo de pessoal no setor público”, em abstrato, pois justamente as variáveis que melhor explicam determinado "tamanho" são o tempo e o espaço de cada caso ou experiência concreta. Em outras palavras, está se falando das diversas trajetórias históricas em curso e dos diversos contextos - territoriais, sociais, políticos, econômicos etc. No livro Burocracia e Ocupação no Setor Público Brasileiro parte-se da premissa de que a história e as instituições importam, de modo que a configuração atual do Estado brasileiro é resultante de determinado contexto e momento histórico, portanto incomparáveis - como recurso didático simplificador - a quaisquer outros casos concretos.

\section{Tendências da ocupação no setor público brasileiro}

O marco de referência analítico para este estudo provém de uma interpretação de conjunto das políticas públicas adotadas no período e não só da descrição das políticas de administração de pessoal explicitadas em cada contexto governamental. Segundo Cardoso Jr. (2011), “as políticas econômicas e sociais têm maior potencial para gerar tendências e problemas peculiares à ocupação do setor público do que as políticas propriamente administrativas".

Pode-se afirmar que as tendências de ocupação são expressões dessas políticas públicas amplas, embora em muitas situações faltem dados confiáveis para se chegar a uma conclusão a seu respeito e para se estabelecer qualquer relação de causalidade entre um e outro aspecto. Os problemas da ocupação pública devem ser entendidos como geradores de impasses políticos que, tampouco, podem ser resolvidos mediante medidas derivadas unicamente da política administrativa de gestão de pessoal, visto que tais problemas estão relacionados fundamentalmente ao cenário macroeconômico e às estratégias adotadas para o desenvolvimento do país.

Entre 1995 e 2010, os governos de Fernando Henrique Cardoso (FHC) e Luiz Inácio Lula da Silva (Lula) estabeleceram políticas de administração de pessoal cujos efeitos se desdobraram para além da ocupação na esfera federal, não só porque algumas dessas políticas se consubstanciaram em novas bases constitucionais e legais, como também porque deram origem a medidas e incentivos que afetaram o crescimento, a distribuição e o modo de 
vinculação de pessoal em todo o âmbito federativo.

No primeiro mandato do Governo FHC, houve um esforço concentrado de produção de documentos e diretrizes explícitas que tinham sua fundamentação no Plano Diretor da Reforma do Aparelho do Estado, de 1995. A administração gerencial preconizada no plano apresenta um conjunto de diretivas bem conhecidas: autonomia financeira e administrativa de certas entidades públicas não estatais, retorno do regime contratual (celetista) para funções não essenciais do Estado, generalização da avaliação de desempenho dos servidores, possibilidade de demissão do servidor por insuficiência de desempenho e excesso de quadros, reorganização das carreiras, especialmente nas funções essenciais do Estado etc. Algumas dessas diretivas foram inicialmente implementadas mediante a Emenda Constitucional n ${ }^{\circ} 19$ (EC 19), de 1998. De forma paralela e mais célere em seus efeitos institucionais, a política de desestatização levou à criação das agências reguladoras, inicialmente nas áreas de telecomunicações e de energia elétrica, logo se estendendo a áreas mais ou menos tradicionais, como saúde e transportes.

Foram concebidos, nesse mesmo período, os planos de demissão voluntária (PDV) dos servidores federais (e de outros níveis de governo), de acordo com modelo encetado no Governo Collor. O governo federal buscou dar exemplo para as demais esferas federativas, ativando seus planos de demissão em conformidade com objetivos de contenção global dos gastos públicos. No entanto, o resultado desses planos, em termos da diminuição do estoque de pessoal ativo, foi bem menor do que o esperado. A medida mais significativa para a redução do pessoal ativo ocorreu por meio da contenção do número de ingressados por concurso público e do aumento das aposentadorias, em função da expectativa de perdas salariais por parte dos servidores.

No segundo mandato do Governo FHC, em um contexto de séria crise cambial, prevalece uma orientação fiscalista, caracterizada por fortes restrições ao gasto com pessoal. Tal orientação culminaria, em 2000, com a edição da Lei de Responsabilidade Fiscal (LRF), que consolidou vários dispositivos legais anteriores, como a Lei Camata, em vigor desde 1995. De um modo geral, entre 1999 e 2002, as prioridades fiscais se impuseram no campo da gestão de pessoal do setor público e tiveram poder predominante em relação às propostas de modernização do aparato administrativo de estado. Por exemplo, na esfera federal, não houve praticamente admissão de novos servidores - nem mesmo para as carreiras essenciais de estado, tão incentivadas pelo plano da reforma administrativa.

Assim, no período do segundo mandato, toda a ênfase política, posta inicialmente na modernização gerencialista da administração pública, deslocou-se para duas outras prioridades: a contenção fiscal das despesas públicas, especialmente as de pessoal, e a desestatização modernizadora, acompanhada do fortalecimento do papel das agências reguladoras. Segundo dados da Rais, existiam em 1991 mais de 20 mil trabalhadores celetistas contratados por empresas de economia mista do governo federal, que ficaram reduzidos, em 2003, a cerca de seis mil, graças ao processo de desestatização que, na verdade, não se constituiu numa medida de administração de empresas públicas pelo Estado, mas, sim, em um componente estratégico da política de liberalização econômica, que visava transferir ao setor privado parte 
importante do estoque de ativos do setor público.

Em contraposição ao primeiro mandato do Governo FHC, as políticas de gestão de pessoal do setor público no Governo Lula, não obstante terem trazido elementos novos e auspiciosos, foram tratadas de modo sumário e em escassos documentos, talvez como reflexo de certa ausência de consenso acerca de qual estratégia política seguir para o tema dos recursos humanos no setor público. Diversas medidas de modernização administrativa continuaram a ser praticadas, mas pouco se escreveu sobre o assunto e a todo custo se evitou o uso da expressão "Reforma do Estado".

$\mathrm{O}$ aspecto de continuidade deve-se, sobretudo, à preservação da orientação fiscal, um dos três pilares essenciais da política macroeconômica, ao lado da manutenção do câmbio apreciado e do combate à inflação pelo regime de metas. Contudo, o novo cenário de crescimento da economia, que teve início em 2004, veio a favorecer o início de uma fase de expansão do quadro de pessoal da administração federal, bem como a política de ajustes graduais da remuneração dos servidores. Simultaneamente, decidiu-se pela reabertura dos concursos públicos dirigidos para pessoal permanente e temporário em áreas prioritárias, incluindo carreiras estratégicas e as agências reguladoras. ${ }^{2}$ Esses concursos tiveram como objetivo adicional substituir os chamados "terceirizados", ou seja, os contratados informais de cooperativas e entidades privadas diversas, bem como os contratados via agências internacionais. Em vários momentos, desde o final do Governo FHC, o objetivo de substituir os terceirizados por concursados foi acertado com o Ministério Público (MP) e o Tribunal de Contas da
União (TCU), mediante a assinatura de Termos de Ajuste de Conduta (TAC). Ainda assim, em 2009, o TCU produziu um relatório demonstrando a persistência de nada menos que 28.567 servidores em situação informal na administração pública federal, direta e indireta.

Um dos aspectos inovadores da política de pessoal do Governo Lula veio mediante a adoção de mesas de negociação com servidores federais, no âmbito do Ministério do Planejamento, Orçamento e Gestão (MPOG), que funcionaram com regularidade. ${ }^{3}$ Esse ministério também se dedicou a formular novas bases para a autonomia gerencial da administração pública indireta. Para tanto, elaborou um projeto específico em torno da figura jurídica da fundação pública de direito privado (conhecida como Fundação Estatal), já regulamentada por várias unidades federadas (UF), mas ainda postergada à votação sine die pelo Congresso Nacional, devido a pressões exercidas pelas corporações de servidores. ${ }^{4}$ Seguindo em direção similar, de apoio ao crescimento do espaço de autonomia administrativa e financeira da administração pública, foram divulgadas as diretrizes produzidas por uma comissão de juristas que se prontificaram a colaborar com aquele ministério na montagem de uma proposta para o estabelecimento de uma nova Lei Orgânica da Administração Pública Federal. ${ }^{5}$

Como síntese, o Quadro 1 distingue as principais diretrizes de administração pública e de política de pessoal nos governos FHC e Lula.

Estreitamente relacionadas com os objetivos de contenção de gastos com pessoal, embora pelo lado do sistema de aposentadorias e pensões, as reformas do sistema previdenciário tiveram forte 


\section{Quadro 1: Governos FHC e Lula - principais diretrizes nos campos da administração pública e das políticas de pessoal}

\begin{tabular}{|c|c|}
\hline \multirow{8}{*}{ Governo FHC } & $\begin{array}{l}\text { Autonomia gerencial nas entidades públicas não estatais em con- } \\
\text { trato de gestão (organizações sociais são criadas pioneiramente } \\
\text { pelo Estado de São Paulo em 1998) }\end{array}$ \\
\hline & Demissão e licença temporária incentivadas \\
\hline & $\begin{array}{l}\text { Limites legais fixados para despesas com pessoal (de acordo } \\
\text { com a Lei de Responsabilidade Fiscal de 2000) }\end{array}$ \\
\hline & Empregados celetistas admitidos por processo seletivo público \\
\hline & $\begin{array}{l}\text { Avaliação do desempenho individual do servidor ou } \\
\text { empregado }\end{array}$ \\
\hline & $\begin{array}{l}\text { Possibilidade de demissão por insuficiência de desempenho e } \\
\text { por excesso de quadros, avaliado segundo limites fiscais }\end{array}$ \\
\hline & $\begin{array}{l}\text { Carreiras e concursos públicos organizados para as funções } \\
\text { essenciais de Estado }\end{array}$ \\
\hline & Criação das agências reguladoras e seu quadro de pessoal próprio \\
\hline \multirow{7}{*}{ Governo Lula } & $\begin{array}{l}\text { Autonomia gerencial em entidades públicas da administração } \\
\text { indireta (projeto de Fundações Estatais e proposta de Lei Orgâ- } \\
\text { nica da Administração Pública Federal) }\end{array}$ \\
\hline & Mesas de negociação para questões de gestão de pessoal \\
\hline & $\begin{array}{l}\text { Reabertura de concursos para servidores temporários e perma- } \\
\text { nentes de órgãos públicos e agências reguladoras }\end{array}$ \\
\hline & $\begin{array}{l}\text { Realocação de pessoal na estrutura de carreiras e ordenamento } \\
\text { das carreiras de Estado }\end{array}$ \\
\hline & $\begin{array}{l}\text { Substituição de pessoal ocupado em atividades-fim com } \\
\text { contrato informal ou contratado via agências internacionais }\end{array}$ \\
\hline & $\begin{array}{l}\text { Limites legais fixados para despesas com pessoal (de acordo } \\
\text { com a Lei de Responsabilidade Fiscal de 2000) }\end{array}$ \\
\hline & $\begin{array}{l}\text { Reajustes graduais da remuneração, com destaque para carreiras } \\
\text { de Estado }\end{array}$ \\
\hline
\end{tabular}

Fonte: Elaboração própria.

impacto sobre a estrutura da ocupação no setor público. Os períodos de discussão legislativa e de aprovação das reformas previdenciárias foram marcados por grande crescimento da demanda por aposentadorias, importando em diminuição considerável do número de servidores ativos. Para ilustrar os resultados dos fatores políticos, de acordo com quatro diferentes contextos governamentais, a 
Tabela 1 apresenta a evolução anual do estoque de ativos, das aposentadorias e dos admitidos por concurso público.

A despeito do discreto crescimento do estoque total de ativos obtido no período dos dois mandatos do Governo Lula, o número de militares e servidores civis registrado em 2010 ainda era inferior ao de 1991. Percebe-se, por esse quadro, o efeito de diminuição do pessoal ativo ocasionado pela "corrida à aposentadoria", que ocorreu associada às fases de votação das reformas previdenciárias, nos anos 1991,1995 a 1998 e 2003.
Sabe-se que o principal determinante da ocupação no setor público está baseado na disponibilidade orçamentária para custeio e investimento. No entanto, a dimensão financeira da manutenção de pessoal ativo e inativo depende das três dimensões de políticas públicas, já mencionadas, que interagem entre si: políticas administrativas, previdenciárias e fiscais. Essas dimensões estiveram longe de ser congruentes entre si e geraram problemas diversos, tais como a corrida para a aposentadoria e a utilização de pessoal terceirizado. A partir de 2003, o número

Tabela 1: Brasil, Administração Federal, 1991 a 2010: evolução anual do estoque de ativos (militares e servidores civis), das aposentadorias e dos admitidos por concurso

\begin{tabular}{|c|c|c|c|c|c|c|}
\hline $\begin{array}{l}\text { Contexto econômico e } \\
\text { político }\end{array}$ & Ano & $\begin{array}{c}\text { Total deAtivos } \\
\text { (civis e militares) }\end{array}$ & $\begin{array}{r}\text { Total deAtivos } \\
\text { (apenas civis) }\end{array}$ & $\begin{array}{l}\text { Aposentados } \\
\text { no ano }\end{array}$ & $\begin{array}{c}\text { Admitidos por } \\
\text { concurso público } \\
\text { no ano }\end{array}$ & $\begin{array}{l}\text { Var. } \% \\
\text { Ativos } \\
\text { (civis) }\end{array}$ \\
\hline \multirow{4}{*}{$\begin{array}{l}\text { Crise e estagnação } \\
\text { (Collor e Itamar) }\end{array}$} & 1991 & 991.996 & 661.996 & 46.196 & - & \multirow{4}{*}{$-2,8$} \\
\hline & 1992 & 998.021 & 683.618 & 21.190 & - & \\
\hline & 1993 & 969.096 & 654.723 & 14.199 & - & \\
\hline & 1994 & 964.032 & 641.564 & 17.601 & - & \\
\hline \multirow{4}{*}{$\begin{array}{l}\text { Reforma do Estado } \\
\text { (FHC) }\end{array}$} & 1995 & 951.585 & 630.763 & 34.253 & 19.675 & \multirow{4}{*}{$-10,5$} \\
\hline & 1996 & 929.375 & 606.952 & 27.546 & 9.927 & \\
\hline & 1997 & 900.128 & 578.680 & 24.659 & 9.055 & \\
\hline & 1998 & 841.851 & 564.320 & 19.755 & 7.815 & \\
\hline \multirow{4}{*}{ Restrição fiscal (FHC) } & 1999 & 866.799 & 545.333 & 8.783 & 2.927 & \multirow{4}{*}{$-2,7$} \\
\hline & 2000 & 864.408 & 536.321 & 5.951 & 1.524 & \\
\hline & 2001 & 857.283 & 531.296 & 6.222 & 660 & \\
\hline & 2002 & 809.975 & 530.662 & 7.465 & 30 & \\
\hline \multirow{8}{*}{$\begin{array}{l}\text { Fortalecimento da } \\
\text { capacidade de Estado } \\
\text { (Lula) }\end{array}$} & 2003 & 856.236 & 534.392 & 17.453 & 7.220 & \multirow{4}{*}{7,3} \\
\hline & 2004 & 884.091 & 538.077 & 6.486 & 16.122 & \\
\hline & 2005 & 873.447 & 548.210 & 5.789 & 12.453 & \\
\hline & 2006 & 887.579 & 573.341 & 6.658 & 22.112 & \\
\hline & 2007 & 896.333 & 573.727 & 8.156 & 11.939 & \multirow{4}{*}{4,8} \\
\hline & 2008 & 913.417 & 583.367 & 10.654 & 19.360 & \\
\hline & 2009 & 926.799 & 601.117 & 10.384 & 29.728 & \\
\hline & 2010 & 970.605 & 630.542 & 13.722 & 36.600 & \\
\hline
\end{tabular}

Fonte: Boletim de Recursos Humanos, Ministério do Planejamento. Elaboração própria. 
de admitidos por concurso, a despeito dos compromissos assumidos perante o MP e o TCU, nunca foi suficiente para acabar com o problema do pessoal com vínculo precário, que é uma situação grave do ponto de vista do princípio da legalidade da ação do Estado.

É evidente que as esferas administrativas dos estados e municípios são afetadas por cada uma das conjunturas mencionadas do governo federal, como também o são por determinantes gerais que se situam nos planos das políticas públicas, especialmente nas políticas fiscais e previdenciárias. Quando se examina o conjunto da ocupação no setor público brasileiro a partir de 1995, destacam-se várias tendências que a seguir serão identificadas através de dados procedentes da Rais - e comentadas de forma bastante sintética.

\section{Enquadramento metodológico e} principais tendências a partir de dados sumários

Metodologicamente, a ocupação no setor público está constituída pela somatória dos que mantêm vínculo institucional direto e indireto com a administração pública. ${ }^{6} \mathrm{O}$ vínculo direto corresponde ao pessoal militar, aos estatutários e aos não estatutários, que, por sua vez, incluem os celetistas e os informais. O contrato de trabalho para prestação de serviços finais de uma dada instituição é caracterizado como irregular pelo Ministério Público (MP) sempre que contraria a norma constitucional que requer a admissão por intermédio de concurso. Nesse caso, a categoria de informalidade ou precariedade do trabalho não implica necessariamente a não observância de direitos do trabalhador, mas, sim, condição que contraria o princípio da legalidade da ação do Estado. Deve ser observado, ademais, que o conceito de ocupação direta na administração pública exclui os vínculos de trabalho com empresas estatais e de economia mista, embora tais vínculos possam ser considerados para efeito de comparação.

Por sua vez, o vínculo indireto resulta de relações contratuais criadas pelas instituições do Estado com entidades privadas, com ou sem fins lucrativos, que colaboram para o alcance de suas funções. Pode-se originar por meio de empresas que fornecem mão de obra para serviços

“Os períodos de discussão legislativa e de aprovação das reformas

previdenciárias

foram marcados

por grande crescimento da demanda por aposentadorias, importando em diminuição considerável do número de servidores ativos."

gerais (copeiros, serventes, porteiros etc.), bem como pela interveniência de fundações de apoio, organizações sociais e entidades similares que compõem o setor "público não estatal", conforme a nomenclatura adotada pelo projeto de Reforma Administrativa de 1995. Essa distinção é relevante no contexto de discussão, porque, em anos recentes, verifica-se a tendência a substituir os 
ocupados com vínculo direto pelos ocupados com vínculo indireto. ${ }^{7}$

Do modo como aqui foi definido, o conceito de ocupação no setor público busca evitar conflito e contradição de acepções, representando alternativa ao conceito de "emprego público". No contexto jurídico-administrativo nacional, emprego público corresponde ao vínculo celetista, segundo consta da Constituição, por contraposição ao vínculo estatutário. O servidor estatutário, que hoje é a grande maioria, não é um empregado, no sentido estrito da palavra, porque ele se caracteriza por submeter-se a um estatuto que descreve seus deveres e direitos e, portanto, juridicamente não mantém relação contratual de emprego com a administração pública.

\section{Evolução da ocupação no setor público em comparação com outros setores da economia}

Entre 2003 e 2010, a ocupação na administração pública brasileira registrou acréscimo de 30,2\%, de acordo com os dados da Rais/MTE (Tabela 2). O maior crescimento ocorreu no setor municipal
(39,3\%), seguido do federal $(30,3 \%)$ e do estadual (19,1\%). Por sua vez, as empresas estatais registraram no período modesto aumento $(11,5 \%)$, o que demonstra a persistência da diretriz política de baixa estatização do setor produtivo estatal, implantada na década de $1990{ }^{8}$

Pelo lado do setor organizacional privado, observa-se que o número de vínculos em empresas aumentou em $62,3 \%$, alcançando mais que o dobro do crescimento da ocupação da administração pública, desempenho que seguramente resulta da significativa expansão das atividades produtivas ocorrida no período.

Desta forma, pode-se afirmar que o aumento dos vínculos no setor público está longe de ser exorbitante, por motivos que transparecem na Tabela 2:

i) o percentual de vínculos nas três esferas públicas, em relação ao total de vínculos formais da economia, diminuiu, passando de $25,2 \%$ a $21,8 \%$;

ii) a taxa de crescimento da ocupação da administração pública $(30,2 \%)$ é bem menor que a taxa do conjunto do setor privado $(58,6 \%)$;

Tabela 2: Brasil, 2003 e 2010: evolução dos vínculos de trabalho nos setores público e privado da economia

\begin{tabular}{c|r|r|r|r|r}
\hline \multicolumn{1}{c|}{ Natureza Jurídica } & $\mathbf{2 0 0 3}$ & $\mathbf{2 0 1 0}$ & $\begin{array}{c}\text { Var (\%) } \\
\mathbf{2 0 0 3 - 1 0}\end{array}$ & $\begin{array}{c}\text { Part. (\%) } \\
\mathbf{2 0 0 3}\end{array}$ & $\begin{array}{c}\text { Part. (\%) } \\
\mathbf{2 0 1 0}\end{array}$ \\
\hline Administração Pública & 7.221 .733 & 9.399 .738 & 30,2 & 25,2 & 21,8 \\
\hline Setor Público Federal & 727.547 & 947.936 & 30,3 & 2,5 & 2,2 \\
\hline Setor Público Estadual & 2.946 .374 & 3.508 .835 & 19,1 & 10,3 & 8,1 \\
\hline Setor Público Municipal & 3.547 .812 & 4.942 .967 & 39,3 & 12,4 & 11,5 \\
\hline Empresas Estatais & 738.424 & 823.341 & 11,5 & 2,6 & 1,9 \\
\hline Setor Privado Organizacional & 20.734 .028 & 32.887 .395 & 58,6 & 72,3 & 76,3 \\
\hline Empresas Privadas & 18.489 .218 & 30.012 .389 & 62,3 & 64,4 & 69,6 \\
\hline Entidades Sem Fins Lucrativos & 2.244 .810 & 2.875 .006 & 28,1 & 7,8 & 6,7 \\
\hline Total dos Setores Organizacionais & $\mathbf{2 8 . 6 9 4 . 1 8 5}$ & $\mathbf{4 3 . 1 1 0 . 4 7 4}$ & $\mathbf{5 0 , 2}$ & $\mathbf{1 0 0 , 0}$ & $\mathbf{1 0 0 , 0}$ \\
\hline
\end{tabular}

Fonte: Rais/MTE 
iii) a taxa de crescimento da ocupação da administração pública $(30,2 \%)$ é comparável à taxa de crescimento dos vínculos das entidades sem fins lucrativos $(28,1 \%)$;

iv) em 2010, as três esferas da administração pública acumulavam somente $21,8 \%$ do total de vínculos, enquanto o setor privado representava $76,3 \%$.

\section{Forte processo de municipalização da ocupação pública}

De acordo com a Tabela 3, em 2010, os vínculos municipais passaram a representar nada menos que 52,6\% do total do setor público. A desconcentração desses vínculos no período examinado se deu principalmente a partir dos estados aos municípios, criando nova realidade para as políticas de controle do gasto público, assim como benefícios consideráveis para a efetividade das políticas sociais. ${ }^{9}$ educação, saúde e assistência social. No período analisado, as ocupações que mais cresceram foram: psicólogos, professores do ensino fundamental, técnicos de programação, enfermeiros, fisioterapeutas e advogados.

Tanto os serviços de saúde quanto os de educação caracterizam-se por serem intensivos no emprego de força de trabalho, e seu impacto tem sido considerável para a expansão da ocupação pública municipal. ${ }^{10}$

\section{Aumento proporcional dos vínculos estatutários}

No período situado entre 1995 e 2010, ao contrário do que pregavam as diretrizes da Reforma Administrativa, os vínculos estatutários - que melhor traduzem os ideais da burocracia weberiana - afirmaram-se como sendo os preferenciais no setor público brasileiro. Por sua vez, os

Tabela 3: Brasil, 1995, 2002 e 2010: percentual de vínculos diretos da ocupação do setor público, segundo esfera administrativa

\begin{tabular}{l|c|c|c}
\hline Ocupação no setor público & $\mathbf{1 9 9 5}$ & $\mathbf{2 0 0 2}$ & $\mathbf{2 0 1 0}$ \\
\hline Número de vínculos diretos & 5.515 .594 & 6.998 .140 & 9.399 .738 \\
\hline Federal (\%) & 15,6 & 11,5 & 10,1 \\
\hline Estadual (\%) & 45,3 & 41,5 & 37,3 \\
\hline Municipal (\%) & 39,1 & 47,0 & 52,6 \\
\hline
\end{tabular}

Fonte: Rais. Exclui empresas estatais e entidades públicas autônomas. Elaboração própria

Envolvendo atualmente um contingente expressivo de cerca de 5 milhões de vínculos, a expansão da ocupação no setor municipal é a principal tendência observada na administração pública e evidencia que a prestação de serviços aos cidadãos é cada vez mais realizada pelas prefeituras municipais, envolvendo áreas intensivas de geração de vínculos de trabalho, tais como: empregados celetistas se tornaram uma parcela reduzida, representando cerca de 10\% dos estatutários. Processos seletivos públicos para contratação de celetistas, conforme previstos na Emenda Constitucional $\mathrm{n}^{\circ} 19$, não foram aplicados e a queda no número desses vínculos se deu de forma inexorável por efeito da aposentadoria de seus ocupantes. Assim, o percentual de 
estatutários em relação a celetistas cresceu de $78,5 \%$ para $90 \%$ nesse período (Tabela 4). instam os gestores municipais a promoverem concurso público. ${ }^{11}$

Tabela 4: Brasil, 1995, 2002 e 2010: percentual de vínculos celetistas e estatutários no conjunto do setor público

\begin{tabular}{l|r|r|r|r|r}
\hline Tipo de vínculo & $\mathbf{1 9 9 5}$ & $\mathbf{2 0 0 2}$ & $\mathbf{2 0 1 0}$ & Var. 95 -02 & Var. 02 -10 \\
\hline $\begin{array}{l}\text { Celetistas } \\
\text { permanentes }\end{array}$ & 1.235 .540 & 873.583 & 582.673 & $-29,3$ & $-33,3$ \\
\hline Estatutários & 4.516 .170 & 4.427 .177 & 5.300 .760 & $-2,0$ & 19,7 \\
\hline \% Estatutários & 78,5 & 83,5 & 90,0 & - & - \\
\hline
\end{tabular}

Fonte: Rais. Exclui empresas estatais e entidades públicas autônomas. Elaboração própria

Entre 1995 e 2002, verifica-se a diminuição acentuada do número de celetistas $(-29,3 \%)$ e a diminuição discreta dos estatutários (-2\%). Mas, na segunda fase desse período, entre 2002 e 2010, a expansão do quadro de ativos do setor público se fez mediante acentuado crescimento do número de estatutários (19,7\%); ao passo que os celetistas mantiveram-se em processo de redução $(-33,3 \%)$.

Contudo, é preciso salientar que uma parte importante dos vínculos dos serviços de saúde e educação na administração municipal tem natureza jurídica contestável, ou seja, precária. Não são poucas as intervenções do MP que clamam pela resolução do problema e
Elevação do nível de escolaridade da força de trabalho no setor público

Com o propósito de avaliar o nível de educação geral, é utilizado aqui o indicador que consiste no percentual dos vínculos com escolaridade acima do nível médio. Esse indicador é composto pela proporção de todos os vínculos com curso superior incompleto e completo e, ainda, os com pós-graduação, em relação ao total de vínculos de cada esfera administrativa. $^{12}$

As informações da Rais para o período evidenciam considerável melhoria da educação geral nas três esferas administrativas, registrada especialmente no período de 2002 a 2010 (Tabela 5). No

Tabela 5: Brasil, 1995, 2002 e 2010 - percentual de vínculos diretos da ocupação do setor público com educação maior que ensino médio, por esfera administrativa

\begin{tabular}{l|l|l|l}
\hline Esfera & $\mathbf{1 9 9 5}$ & $\mathbf{2 0 0 2}$ & $\mathbf{2 0 1 0}$ \\
\hline Federal & 46,1 & 38,9 & 50,7 \\
\hline Estadual & 29,7 & 39,7 & 49,4 \\
\hline Municipal & 15,6 & 21,6 & 33,7 \\
\hline Total & $\mathbf{2 7 , 0}$ & $\mathbf{3 1 , 1}$ & $\mathbf{4 1 , 3}$ \\
\hline
\end{tabular}

Fonte: Rais. Exclui empresas estatais e entidades públicas autônomas. Elaboração própria 
âmbito federal, chama atenção o fato de que houve uma queda do nível de educação geral, entre 1995 e 2002, de 46,1\% para $38,9 \%$. Isto significa que foram justamente os trabalhadores com maior nível de escolaridade que mais se aposentaram no período. Contudo, no período seguinte, eleva-se o nível de escolaridade, alcançando $50,7 \%$ em 2010.

Por sua vez, os que trabalhavam na esfera estadual apresentavam praticamente o mesmo nível de escolaridade dos que se situavam na esfera federal. Os municípios obtiveram os avanços mais significativos nesse quesito entre 2002 e 2010 , tendo o indicador passado de 21,6\% para 33,7\%.

\section{Diminuição de ocupados em fun-} ções administrativas (atividades-meio)

A tendência à diminuição dos ocupados em funções administrativas intermediárias é um fenômeno bem conhecido e que certamente decorre da utilização crescente de tecnologias da informação (TI). Uma série de atividades que antes tinham o caráter de apoio administrativo e eram exercidas tipicamente por secretários, escriturários, datilógrafos, auxiliares administrativos, entre outros, puderam ser incorporadas ao perfil dos diferentes tipos de profissionais ocupados em cargos de direção, assessoria e controle, que são obrigados a lidar cotidianamente com a TI para o exercício de suas tarefas.
Todavia, segundo os dados da Rais, as afirmações acima são validadas apenas para as esferas federal e estadual, nas quais houve um decréscimo dos vínculos de serviços administrativos de $9,1 \%$ e $21,8 \%$ respectivamente, entre 2002 e 2010 (Tabela 6). Já nos municípios, o número de trabalhadores administrativos cresceu $11,4 \%$ nesse período. Uma hipótese a considerar diante desse resultado é que o processo de difusão da TI tem sido mais lento na administração municipal, por fatores diversos.

Vem crescendo a demanda por pessoal técnico-profissional para apoio às funções de TI. A diminuição do número de pessoal administrativo corresponde à tendência em sentido inverso, que é o aumento dos profissionais e técnicos de informática, em ritmo acelerado. O número de pessoal especializado em TI é mais elevado na esfera estadual, mas a taxa de crescimento maior dá-se no âmbito federal. Verifica-se um número ainda reduzido de técnicos de TI nos municípios.

\section{Tendências de gênero}

A ocupação do setor público se faz de modo diferenciado quanto ao gênero, sendo que as mulheres constituem minoria na administração federal e maioria nos estados e municípios (Tabela 7). O que explica tal participação diferenciada é possivelmente o fato de que o número de mulheres é predominante nas funções de saúde, assistência social e educação, as quais,

Tabela 6: Brasil, 2002 e 2010. Trabalhadores de serviços administrativos por esfera

\begin{tabular}{l|c|c|c}
\hline Esfera & $\mathbf{2 0 0 2}$ & $\mathbf{2 0 1 0}$ & \% Var. \\
\hline Federal & 46,1 & 38,9 & 50,7 \\
\hline Estadual & 29,7 & 39,7 & 49,4 \\
\hline Municipal & 15,6 & 21,6 & 33,7 \\
\hline Total & $\mathbf{2 7 , 0}$ & $\mathbf{3 1 , 1}$ & $\mathbf{4 1 , 3}$ \\
\hline
\end{tabular}

Fonte: Rais. Elaboração própria. 
como já mencionado, são assumidas em maior parte pelos estados e municípios. A tendência evidenciada pelos dados ocorre no sentido de que a participação feminina diminua nos estados e aumente nos municípios e na esfera federal.

A despeito de a participação feminina total na esfera federal ser menor do que a dos homens, registra-se percentual maior de mulheres ocupando cargos superiores e de direção nessa esfera, em comparação com os homens. Nos estados, os homens têm participação semelhante à das mulheres e, nos municípios, os homens têm participação relativa maior nessas funções hierarquicamente diferenciadas.

Outro resultado interessante em relação a gênero é que, medida por salários mínimos, a renda média mensal das mulheres ultrapassa a dos homens na esfera federal, ocorrendo o inverso nas duas outras esferas (Tabela 8). Portanto, no governo federal, as mulheres, proporcionalmente ao seu número, ocupam funções mais elevadas na hierarquia e têm renda maior que a dos homens.

\section{Dimensão e controle das despesas com pessoal}

A questão sobre a supostamente elevada magnitude dos gastos públicos com pessoal suscita muito interesse, devido a ter se tornado divisor de águas entre diferentes visões políticas acerca do papel do Estado no processo de desenvolvimento. Desde o início da década de 1990, marcada por uma postura governamental thatcheriana de combate à burocracia de estado, a cada informação que a imprensa divulga sobre o número de servidores ou o montante do gasto público com pessoal, determinadas

Tabela 7: Brasil, 1995, 2002 e 2010 - percentual de participação feminina por esfera administrativa do setor público

\begin{tabular}{l|l|l|l}
\hline Esfera & $\mathbf{1 9 9 5}$ & $\mathbf{2 0 0 2}$ & $\mathbf{2 0 1 0}$ \\
\hline Federal & 31,9 & 32,1 & 35,1 \\
\hline Estadual & 59,6 & 58,4 & 57,3 \\
\hline Municipal & 61,7 & 62,4 & 64,0 \\
\hline Total & $\mathbf{5 6 , 6}$ & $\mathbf{5 7 , 2}$ & $\mathbf{5 8 , 6}$ \\
\hline
\end{tabular}

Fonte: Rais. Elaboração própria.

Tabela 8: Brasil, 2010: renda média mensal (em salários mínimos) por gênero e por esfera administrativa do setor público

\begin{tabular}{l|c|c}
\hline Ano & \multicolumn{2}{|c}{$\mathbf{2 0 1 0}$} \\
\hline Esfera & Homens & Mulheres \\
\hline Federal & 11,1 & 12,2 \\
\hline Estadual & 6,2 & 4,6 \\
\hline Municipal & 3,0 & 2,7 \\
\hline $\begin{array}{l}\text { Renda média mensal } \\
\text { (em salários mínimos) }\end{array}$ & $\mathbf{5 , 5}$ & $\mathbf{3 , 9}$ \\
\hline
\end{tabular}

Fonte: Rais. Elaboração própria. 
correntes de economistas tentam impingir o diagnóstico de que a máquina administrativa está "inchada" e que o gasto com pessoal é excessivo.

Ocorre que, na verdade, não está disponível qualquer parâmetro consensual para validar tal diagnóstico. A única regra que se observa na história recente é que, em momentos de expansão da atividade econômica e da concomitante arrecadação tributária, os governos sentem-se mais estimulados para aumentar os gastos com o aparato administrativo - portanto, não só com pessoal; e em momentos de crise fiscal, impõem ou acatam medidas legais de limitação desses gastos. ${ }^{13}$

Em conclusão, a ocupação do setor público só pode ser considerada excessiva quando avaliada em cotejamento com os resultados de uma conjuntura de crescimento econômico reduzido e queda da arrecadação. Mas uma teoria econômica como a keynesiana afirma que gastos do Estado são importantes para reativar o crescimento em tal conjuntura, especialmente em face de um mercado de trabalho com ampla parcela informal e baixa renda, como é o caso do Brasil. Desse modo, o diagnóstico de excesso de pessoal não dá base suficiente de conhecimento para amparar uma política administrativa de gestão da força de trabalho no setor público.

Outra advertência diz respeito às comparações internacionais. O Brasil tem excelente sistema de monitoramento de gastos com pessoal, mas comparações internacionais só deveriam ser realizadas se a metodologia comparativa conseguisse descontar as peculiaridades da composição desses gastos e do próprio mercado de trabalho brasileiro. Como essa é uma tarefa que extrapola os objetivos sintéticos deste estudo, aqui só será empreendida breve descrição das dimensões e das tendências do gasto com pessoal e dos problemas relacionados com seu controle pelas políticas fiscais.

Para fins de monitoramento das despesas de pessoal do governo geral (as três esferas administrativas) no Brasil, pode-se recorrer a duas fontes de dados: o Sistema Nacional de Contas (SNC), do IBGE, e a Secretaria do Tesouro Nacional (STN). O primeiro informa as despesas com salários e benefícios, enquanto os dados da STN apresentam, em forma agregada, as despesas com ativos e inativos, na medida em que estão voltados para o acompanhamento do cumprimento da LRF.

A partir dessas duas fontes (Gráfico 4), conclui-se que as despesas com pessoal das três esferas administrativas (governo geral) decresceram relativamente a partir de 2002, mas voltaram a aumentar a partir de 2005, sem, contudo, alcançar o patamar de 2002. Há uma tendência similar para o governo federal, quando se consideram as despesas com ativos e inativos como percentual do Produto Interno Bruto (PIB).

As despesas com pessoal, considerando o percentual do $\mathrm{PIB}$, foram mais elevadas no ano final do Governo FHC. No Governo Lula, houve aumento em 2005, mas a partir de então se observa discreta diminuição desses gastos, tomando como referência o PIB do ano corrente. ${ }^{14}$

Um retrato da situação atual, quanto ao conjunto dessas despesas, aparece na Tabela 9, para 2009 - último dado disponível, em que se constatou mau desempenho da economia, havendo o PIB se retraído em $0,2 \%$. O governo geral, composto pelas três esferas administrativas, apresentou despesas com pessoal que equivalem a $41,5 \%$ do total de despesas e a $42,1 \%$ do total das receitas.

Por fim, com base no gráfico 5, verificase que a massa salarial no setor público em 


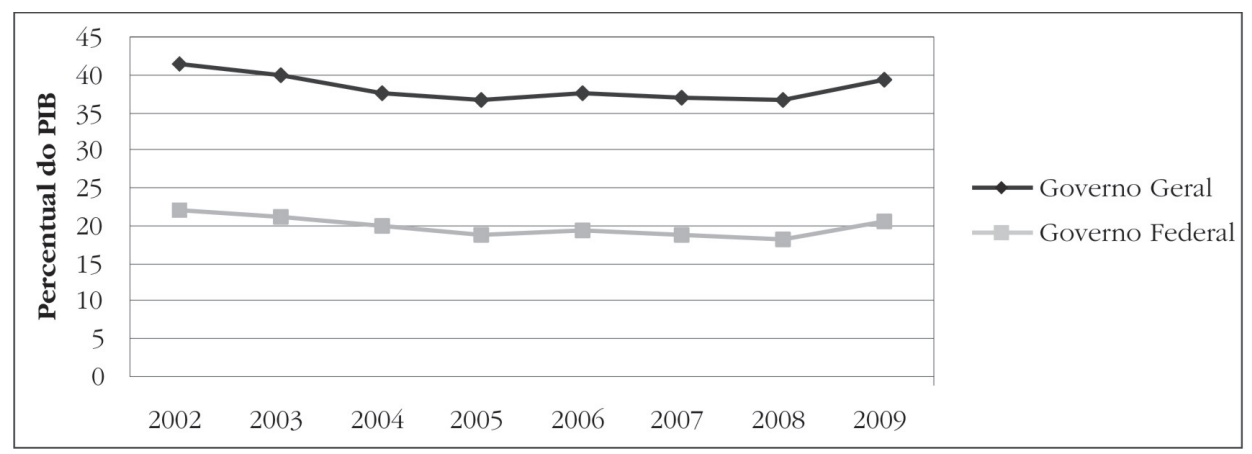

Fonte: Secretaria do Tesouro Nacional

Gráfico 4: Despesas com pessoal como percentual do PIB

Tabela 9: Brasil, 2009: despesas nominais do governo geral (Em R\$ mil) - último dado disponível

\begin{tabular}{l|r|r|r|r}
\hline Tipo de Despesa & $\begin{array}{r}\text { Governo geral } \\
\text { (três esferas) }\end{array}$ & Federal & Estadual & Municipal \\
\hline Total das receitas & 1.226 .901 .202 & 737.062 .261 & 424.915 .547 & 256.910 .195 \\
\hline Total das despesas & 1.162 .752 .222 & 696.996 .253 & 406.439 .348 & 251.303 .423 \\
\hline Pessoal (valor) & 482.549 .217 & 151.652 .813 & 207.934 .962 & 122.961 .442 \\
\hline $\begin{array}{l}\text { Pessoal (\% das } \\
\text { receitas) }\end{array}$ & 42,1 & 24,9 & 50,9 & 44,7 \\
\hline $\begin{array}{l}\text { Pessoal (\% das } \\
\text { despesas) }\end{array}$ & 41,5 & 21,8 & 51,2 & 48,9 \\
\hline Pessoal (\% do PIB) & 14 & 4,3 & 6,2 & \\
\hline
\end{tabular}

Fonte: STN e Banco Central do Brasil (Bacen).

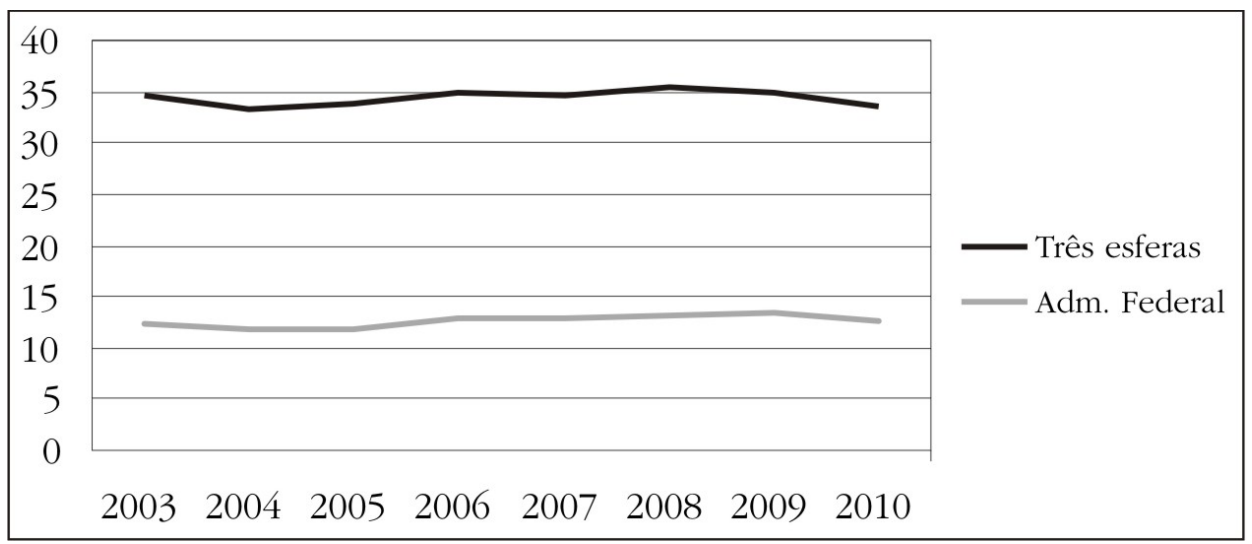

Fonte: Rais. Elaboração própria

Gráfico 5: Evolução da massa salarial do setor público como percentual do setor privado 
relação ao setor privado não apresenta uma tendência clara de crescimento. Com efeito, a massa salarial nas três esferas da administração pública e, isoladamente, na esfera federal, elevou-se a partir de 2006, mas voltou a cair em 2010, mantendo aproximadamente a mesma fração, ou seja, sem gerar qualquer descompasso flagrante com a dinâmica do setor privado. Isso quer dizer que os gastos com pessoal no setor público vêm acompanhando o ritmo de crescimento do emprego e, portanto, da massa salarial do setor privado. É um indício de que o ciclo econômico é um determinante poderoso do ritmo e magnitude de crescimento do emprego público, bem como dos gastos públicos relacionados a ele.

\section{Recomendações de pesquisa para o futuro}

Para além das informações e conclusões resumidas acima, inúmeras outras podem ser extraídas do livro Burocracia e Ocupação no Setor Público Brasileiro, a saber: a respeito da formação histórica da burocracia pública no país; das diretrizes recentes em termos tanto de salários e vencimentos quanto da ocupação em cargos comissionados no poder público federal; de fenômenos sociais e demográficos importantes em curso dentro do Estado, como, por exemplo, as tendências de municipalização da ocupação no setor público, de maior escolarização e profissionalização, de ampliação da presença feminina e de rejuvenescimento da força de trabalho, sobretudo em âmbito federal, entre outras.

Por outro lado, importa registrar algumas importantes lacunas deste estudo, as quais, não obstante, constituem-se em novas pautas de pesquisa aplicada e assessoramento governamental por parte do Ipea, a saber:

- Em que condições vêm se dando os processos seletivos nas três esferas de governo, em especial no nível federal? Os atuais formatos de seleção por concursos públicos padronizados vêm conseguindo atrair e filtrar candidatos com perfis adequados à natureza pública da ocupação e ao cumprimento das exigências institucionais do Estado, em todos os seus níveis?

- Há, nas diversas instâncias do Estado, planos de cargos ou carreiras, progressão funcional e vencimentos, capacitação permanente, flexibilização funcional e preparação para a aposentadoria, considerados adequados e satisfatórios aos diversos objetivos estratégicos do Estado, a médio e longo prazo?

- Como instaurar e cultivar ou desenvolver uma cultura de aprimoramento permanente de desempenho institucional do setor público, inclusive passível de monitoramento ao longo do tempo por meio de indicadores (quantitativos e qualitativos) de desempenho (efetividade, eficácia e eficiência), aplicáveis aos três níveis federativos e também aos três grandes Poderes da República?

Enfim, há questões que merecem esforços institucionais de pesquisa e assessoramento governamental por parte do Ipea (e outros órgãos), visando aprimorar a discussão corrente sobre temas tão complexos, mas absolutamente fundamentais para o Estado brasileiro, no atual momento histórico de retomada de posturas e atitudes mais ativas em prol do desenvolvimento nacional. (Artigo recebido em outubro de 2011. Versão final em novembro de 2011). 


\section{Notas}

1 Para este texto foi realizado esforço de atualização de dados que contemplasse o ano de 2010. Importante destacar que os Comunicados IPEA de números 19 (Emprego Público no Brasil: comparação internacional e evolução recente, de 30 de março de 2009) e 37 (Salários no Setor Público versus Salários no Setor Privado no Brasil, de 10 de dezembro de 2009) já trataram, sob outros recortes, deste mesmo assunto.

2 Para uma síntese dessas medidas (e seus resultados em termos) de recomposição de quadros e de remunerações, ver Moraes et al. (2010).

3 Em palavras de um importante dirigente público de alto escalão do governo federal à época, "no ano de 2002, foram encaminhadas para o Congresso quatro propostas de medidas provisórias que reajustaram as políticas remuneratórias, e isso é resultado do processo de negociação. O que permitiu que se construíssem, em várias áreas da gestão de pessoas, eixos importantes - o primeiro deles é a gestão de competências. Está configurado, a partir de uma orientação dada pelo decreto n 5707 , a definição da política de desenvolvimento de pessoas, que passa a ser conduzida não só pela Secretaria de Recursos Humanos, mas por um comitê de desenvolvimento de pessoas, que é composto pela Secretaria de Recursos Humanos, Secretaria de Gestão e pela Escola Nacional de Administração Pública. Isso permitiu construir um novo modelo para a política de gestão de pessoas, baseado principalmente nos eixos: democratização, gestão por competências, avaliação de desempenho". Para uma visão mais ampla desse assunto, ver o restante desta fala em Cardoso Jr. e Mattos (2011).

4 Em particular, ver Nogueira (2010).

5 Para uma apresentação e qualificação do debate em torno do referido projeto, ver CARDOSO Jr. e Pires (2011).

6 Para a necessária discussão metodológica acerca das opções e alternativas de uso das diferentes bases de dados existentes para este tema, ver Pessoa, Cardoso Jr. e Figueiredo (2011).

7 Para este último caso, ver Pessoa (2011).

8 A classificação de natureza jurídica das organizações públicas e privadas aqui utilizada foi introduzida na RAIS em 2003 e, portanto, impossibilita comparações com períodos anteriores.

9 Para uma abordagem mais ampla acerca deste tema, ver Pessoa (2011).

${ }^{10}$ Este é, inclusive, um dos fatores apontados por Cardoso Jr. (2007) para explicar o crescimento do emprego formal no Brasil na primeira década de 2000.

${ }^{11}$ Com vistas a perceber o impacto da Lei de Responsabilidade Fiscal (LRF) sobre as finanças e as ocupações em nível municipal, ver Kerches e Peres (2010).

12 Para ver, em particular, o padrão de escolaridade dos cargos comissionados do governo federal, ver D'Araújo e Lameirão (2011).

13 Em particular, para a visão dominante na literatura econômica e até mesmo no debate público sobre o tema, ver Organização para Cooperação e Desenvolvimento Econômico (OCDE, 2010). E para uma visão abrangente e crítica desta questão, ver Garcia (2008), além dos capítulos 6, 7 e 8 de Cardoso Jr. (2011).

${ }^{14}$ Um fator que tem pesado nos custos salariais é a média elevada de idade da força de trabalho ativa federal, que se encontra em grande parte nas classes mais altas das carreiras e, portanto, usufruindo de níveis salariais mais elevados. Além disso, a reorganização e expansão das carreiras de Estado pressupõem oferta de cargos com salários competitivos em relação ao mercado de trabalho do setor privado, o que também implica maiores despesas dessa natureza. 


\section{Referências bibliográficas}

CARdoso JR., J. C. De volta para o futuro? As fontes de recuperação do emprego formal no Brasil e as condicões para sua sustentabilidade temporal. Brasília: IPEA, 2007 (Texto para Discussão, $\mathrm{n}^{\circ}$ 1.310).

Macroeconomia e pleno emprego: apontamentos para uma agenda positiva de pesquisa e política pública. In: Vianna, S. W; Bruno, M.; Modenesi, A. (Org.). Macroeconomia para o desenvolvimento: crescimento, estabilidade e emprego. Rio de Janeiro: Ipea, 2010. Vol. único, cap. 11, livro 4. (Projeto Perspectivas do desenvolvimento brasileiro).

. (Org.) Burocracia e ocupação no setor público brasileiro. Brasília: Ipea, 2011. Vol.

5. (Série Diálogos para o Desenvolvimento).

Cardoso Jr., J. C. ; Mattos, F. Elementos para a montagem de um sistema federal de planejamento governamental e gestão pública no Brasil: reflexões preliminares a partir de entrevistas com dirigentes de alto escalão do governo federal em 2009. In: CARDOso JR., J. C. (Org.). A Reinvenção do planejamento governamental no Brasil. Brasília: Ipea, 2011. Vol. 4, cap. 8. (Série Diálogos para o desenvolvimento).

Cardoso Jr., J. C. ; Pires, R. (Orgs.). Desafios contemporâneos à gestão pública no Brasil. Brasília: Ipea, 2011. Vol. 6. (Série Diálogos para o desenvolvimento).

D’Araújo, M. C.; Lameirão, C. Dirigentes públicos federais de alto escalão no governo Lula. In: Cardoso Jr., J. C. (Org.). Burocracia e ocupação no setor público brasileiro. Brasília: Ipea, 2011. Vol. 5, cap. 3. (Série Diálogos para o desenvolvimento).

Garcia, R. C. Despesas correntes da União: visões, omissões e opções. Brasília: Ipea, 2008. (Texto para Discussão n. 1.319).

Kerches, C.; Peres, U. Lei de responsabilidade fiscal, federalismo e políticas públicas: um balanço crítico dos impactos da LRF nos municípios brasileiros. In: CunHA, A.; Aquino, L.; Medeiros, B. (Org.). Estado, instituições e democracia: república. Brasília: Ipea, 2010. Vol. 1, cap. 6, livro 9 (Projeto perspectivas do desenvolvimento brasileiro).

Matтos, F. Emprego público no Brasil: aspectos históricos e evolução recente. In: Cardoso Jr., J. C. (Org.). Burocracia e ocupação no setor público brasileiro. Brasília: Ipea, 2011a. Vol. 5, cap. 6 (Série Diálogos para o desenvolvimento).

MatTos, F. Emprego público em perspectiva internacional: evolução histórica e diferenças nos perfis. In: CARdoso JR., J. C. (Org.). Burocracia e ocupação no setor público brasileiro. Brasília: 2011b. Vol. 5, cap. 8 (Série Diálogos para o Desenvolvimento).

Moraes, M. V. et al. Avanços e desafios na gestão da força de trabalho no Poder Executivo Federal. In: Cunha, A.; Aquino, L.; Medeiros, B. (Orgs.). Estado, instituições e democracia: república. Brasília: Ipea, 2010. Vol. 1, cap. 11, livro 9. (Projeto Perspectivas do Desenvolvimento Brasileiro).

NogueirA, R. P. O desenvolvimento federativo do SUS e as novas modalidades institucionais de gerência das unidades assistenciais. In: Cunha, A.; Aquino, L.; Medeiros, B. (Orgs.). Estado, instituições e democracia: república, livro 9, v. 1, cap. 7. Brasília: Ipea, 2010. Vol. 1, cap. 7, livro 9. (Projeto Perspectivas do Desenvolvimento Brasileiro). 
OCDE. Avaliação da gestão de recursos humanos no governo federal-Brasil 2010. Brasília: OCDE, MPOG, 2010.

PessoA, E. Emprego público e ocupações no serviço público municipal na primeira década de 2000. In: CARdoso Jr., J. C. (Org.). Burocracia e ocupação no setor público brasileiro. Brasília: Ipea, 2011. Vol. 5, cap. 7. (Série Diálogos para o desenvolvimento).

Pessoa, E ; Cardoso Jr., J. C.; Figueiredo, S. Conceitos de emprego público: questões metodológicas e possibilidades de mensuração. In: CARDoso Jr., J. C. (Org.). Burocracia e ocupação no setor público brasileiro. Brasília: Ipea, 2011. Vol. 5, cap. 5 (Série Diálogos para o desenvolvimento).

TCU. Relatório e parecer prévio sobre as contas do governo da república. Nota técnica n 098/2010/DMI/SEGES/MP. 2010. 


\section{Resumo-Resumen-Abstract}

\section{Ocupação no setor público brasileiro: tendências recentes e questões em aberto José Celso Cardoso Júnior e Roberto Passos Nogueira}

Com base neste trabalho, poder-se-ia hoje afirmar com maior segurança que: i) o movimento de recomposição de pessoal no setor público brasileiro, observado durante toda a primeira década de 2000, mostrou-se apenas suficiente para repor praticamente o mesmo estoque de servidores ativos existentes em meados da década de 1990; ii) tampouco se deduz dos dados analisados que os gastos com pessoal tenham saído do controle do governo federal, pois, em termos percentuais, essa rubrica permaneceu praticamente constante ao longo da primeira década de 2000, em um contexto de retomada relativa do crescimento econômico e também da arrecadação tributária; e iii) do ponto de vista qualitativo, evidências da pesquisa indicam que esse movimento atual deve trazer melhorias gradativas ao desempenho institucional, pois vem sendo promovido a partir de critérios meritocráticos de seleção (concursos públicos), e diante disso as atividades-fim, que exigem nível superior de escolarização, são mais contempladas do que as atividades-meio, indicando a possibilidade de maiores impactos sobre a produtividade agregada do setor público; e tem assumido a forma de vinculação estatutária, em detrimento do padrão celetista ou de várias formas de contratação precárias, o que coloca o novo contingente sob direitos e deveres comuns e estáveis, podendo com isso gerar maior coesão e homogeneidade no interior da categoria como um todo, aspecto considerado essencial para um desempenho satisfatório do Estado a longo prazo.

Palavras-chave: ocupação no setor público, gastos com pessoal, desempenho institucional, desenvolvimento brasileiro.

\section{Ocupación en el sector público brasileño: tendencias recientes y cuestiones abiertas José Celso Cardoso Júnior y Roberto Passos Nogueira}

De acuerdo con este trabajo, sería capaz de decir hoy, con mayor seguridad que: i) el restablecimiento del personal en el sector público brasileño, observado durante la primera década del 2000, solo fue suficiente para reemplazar casi la misma población de los activos existentes a mediados de la década de 1990; ii) no se deduce de los datos analizados que los gastos de personal hayan salido del control del gobierno federal, ya que, en términos porcentuales, ese tema se mantuvo prácticamente constante durante la primera década del año 2000 , en un contexto de relativa recuperación del crecimiento económico y de la recaudación de impuestos; y iii) del punto de vista cualitativo, la evidencia de la investigación indica que ese movimiento actual debe llevar a mejoras incrementales en el desempeño de las instituciones debido a que: ha sido seleccionado a partir de criterios meritocráticos, y más para las actividades básicas, que requieren un mayor nivel de escolaridad, indicando la posibilidad de un mejor impacto sobre la productividad agregada en el sector público, y han tomado la forma de vinculación legal, en detrimento de diversas formas de empleo precarias, que pone este nuevo contingente bajo obligaciones y derechos comunes y estables, y esto puede generar una mayor cohesión y homogeneidad dentro de la categoría en su conjunto, que es un aspecto considerado esencial para el funcionamiento satisfactorio del Estado en el largo plazo.

Palabras clave: la ocupación en el sector público, el gasto en personal, el desempeño institucional, el desarrollo de Brasil. 
Brazilian public sector occupation: recenty tendencies and questions that remain opened José Celso Cardoso Júnior and Roberto Passos Nogueira

Based on this work, would be able to say today, with greater security that: i) the restoration of the movement of staff in Brazilian public sector, observed during the first decade of 2000, was only sufficient to replace virtually the same stock that in the mid-1990s, ii) neither be deduced from the data analyzed that personnel expenses have gotten out of control federal government, because, in percentage terms, this item remained virtually constant over the first decade of 2000, in a context of relative recovery of economic growth and also tax collection, and iii) the qualitative point of view, the research evidence indicates that this current movement is to bring incremental improvements to the institutional performance because: has been selected from meritocratic criteria, and more for core activities, which require higher level of schooling than formiddle-activities, indicating the possibility of major impacts on aggregate productivity in the public sector, and have taken the form of statutory linkage to the detriment of the various forms of precarious employment, which puts the new contingent under rights and duties common and stable, and this may generate greater cohesion and homogeneity within the category as a whole, this aspect considered essential for a satisfactory performance of the state in the long term.

Keywords:occupation in the public sector, spending on personnel, institutional performance, the Brazilian development.

José Celso Cardoso Júnior

Economista pela Universidade de São Paulo (USP) e pós-graduado em Economia pela Universidade Estadual de Campinas (UNICAMP). É Técnico de Planejamento e Pesquisa do Instituto de Pesquisa Econômica Aplicada (Ipea) desde 1996. Contato: josecelso.cardoso@ipea.gov.br

Roberto Passos Nogueira

Doutor em Saúde Coletiva pela Fundação Oswaldo Cruz (Fiocruz). É médico e Técnico de Planejamento e Pesquisa do Ipea desde 2004. Contato: roberto.nogueira@ipea.gov.br 